\title{
Surface spectators and their role in relationships between activity and selectivity of the oxygen reduction reaction in acid environments
}

Eduardo G. Ciapina, ${ }^{1,2,3}$ Pietro P. Lopes, ${ }^{1}$ Ram Subbaraman ${ }^{1}$, Edson A. Ticianelli ${ }^{3}$, Vojislav Stamenkovic ${ }^{1}$, Dusan Strmcnik ${ }^{1 \S}$, Nenad M. Markovic ${ }^{1}$

1 Materials Science Division, Argonne National Laboratory, Argonne, IL, USA

2 Faculdade de Engenharia, UNESP - Univ. Estadual Paulista, Guaratinguetá-SP, Brazil.

3 Instituto de Quimica de Sao Carlos, Universidade de Sao Paulo, Sao Carlos-SP, Brazil.

\begin{abstract}
We use the rotating ring disk (RRDE) method to study activity-selectivity relationships for the oxygen reduction reaction (ORR) on $\mathrm{Pt}(111)$ modified by various surface coverages of adsorbed $\mathrm{CN}_{\mathrm{ad}}\left(\Theta_{\mathrm{CNad}}\right)$. The results demonstrate that small variations in $\Theta_{\mathrm{CNad}}$ have dramatic effect on the ORR activity and peroxide production, resulting in "volcano-like" dependence with an optimal surface coverage of $\Theta_{\mathrm{CNad}}=0.3 \mathrm{ML}$. These relationships can be simply explained by balancing electronic and ensemble effects of co-adsorbed $\mathrm{CN}_{\mathrm{ad}}$ and adsorbed spectator species from the supporting electrolytes, without the need for intermediate adsorption energy arguments. Although this study has focused on the $\mathrm{Pt}(111)-\mathrm{CN}_{\mathrm{ad}} / \mathrm{H}_{2} \mathrm{SO}_{4}$ interface, the results and insight gained here are invaluable for controlling another dimension in the properties of electrochemical interfaces.
\end{abstract}

\section{Introduction}

The oxygen reduction reaction (ORR), the cathodic half-cell reaction in fuel cells [1,2], is one class of electrocatalytic reaction exhibiting strong relationships between interfacial properties and reactivity, due its multi-electron reaction nature that includes a number of elementary steps involving different reaction intermediates (e.g., $\mathrm{O}_{2} *, \mathrm{H}_{2} \mathrm{O}_{2} *$, and $\mathrm{OH}^{*}$ )[3-5]. From studying the ORR on well-characterized metal single crystal surfaces it was found that the reaction kinetics varies with the crystal face differently according to the electrolyte used [6], strongly suggesting that structure sensitivity arises mainly from the geometry dependent 
adsorption of spectator species [7-11]. As a consequence, during the ORR metal surfaces are always covered with different kind of spectators, for which the corresponding surface coverage $\left(\Theta_{\mathrm{s}}\right)$ is strongly dependent on a synergy between the substrate-adsorbates energetics, the applied electrode potential and the symmetry match between the geometry of surface atoms and adsorbates. Recently, it has been shown that a Pt(111) electrode modified by an optimal coverage of irreversibly adsorbed $\mathrm{CN}$ species $\left(\Theta_{\mathrm{CNad}}\right)$ can effectively suppress adsorption of undesired tetrahedral oxyanions, while providing sufficient number of free metal sites to effectively chemisorb $\mathrm{O}_{2}$ molecule and to break the O-O bond [12]. It was proposed that adsorption of phosphoric and sulfuric oxyanions on $\mathrm{Pt}(111)-\mathrm{CN}_{\mathrm{ad}}$ are suppressed largely via a steric, siteblocking (ensemble) mechanism [12]. In contrast, the effect of $\mathrm{CN}_{\mathrm{ad}}$ on adsorption of $\mathrm{H}_{\text {upd }}$ and $\mathrm{OH}_{\mathrm{ad}}$ is markedly different, affecting the $\mathrm{Pt}-\mathrm{H}_{\text {upd }}$ and $\mathrm{Pt}-\mathrm{OH}_{\mathrm{ad}}$ energetics via dipole-dipole $\mathrm{CN}_{\mathrm{ad}}{ }^{-}$ $\mathrm{H}_{\mathrm{upd}} / \mathrm{OH}_{\mathrm{ad}}$ interactions (electronic effects) [13]. Combination of these two mechanisms may serve as a basis in finding true functional links between the activity and selectivity of $\mathrm{Pt}(111)$ $\mathrm{CN}_{\mathrm{ad}}$ electrochemical interface in environments containing undesirable bisulfate/phosphate anions.

Given this opportunity, we decided to extend our recent rotating disk exploration of the ORR activity on the $\mathrm{Pt}(111)-\mathrm{CN}_{\mathrm{ad}}$ electrode to encompass utilization of the rotating ring disk method for monitoring $\mathrm{CN}_{\mathrm{ad}}$ surface coverage dependent selective production of peroxide intermediate. Our findings address some key points in selectivity for the ORR at the same time as discuss the importance of adsorbate lateral interactions.

\section{Experimental}

Crystal preparation procedures and electrochemical measurements have been described in previous publications [12,14,15]. Electrode potentials are given versus the reversible hydrogen electrode (RHE), calibrated using $\mathrm{H}_{2}$ oxidation in a separate experiment. Cyanide-modified $\operatorname{Pt}(111)$ electrodes were prepared by immersion of an annealed $\operatorname{Pt}(111)$ single crystal in $0.2 \mathrm{~mol} \mathrm{~L}^{-1} \mathrm{KCN}$ solution for 30 minutes at open circuit, thus forming an irreversibly adsorbed $\mathrm{CN}$ adlayer. After extensive rinsing, the electrode was embedded into the rotating ring-disk 
electrode assembly (RRDE) and transferred into a standard three-compartment electrochemical cell containing $0.05 \mathrm{~mol} \mathrm{~L}^{-1} \mathrm{H}_{2} \mathrm{SO}_{4}$ (EMD) solution saturated with $\mathrm{O}_{2}$, under potential control at $0.27 \mathrm{~V}$. Electrodes with distinct $\Theta_{\mathrm{CNad}}$ were obtained by cycling the $\mathrm{CN}$-modified $\mathrm{Pt}(111)$ electrode between 0.07 and $0.9 \mathrm{~V}$ in a $\mathrm{O}_{2}$-saturated solution at $1600 \mathrm{rpm}$. Base cyclic voltammograms characteristic to a given $\Theta_{\mathrm{CNad}}$ was recorded by purging out the dissolved oxygen by argon for at least 30 minutes under at $0.27 \mathrm{~V}$. The sweep rate for all measurements was $50 \mathrm{mV} \mathrm{s}^{-1}$. Peroxide oxidation signal was measured at the ring held at $1.2 \mathrm{~V}$. Collection efficiency found for the RRDE setup was $0.24 \pm 0.05$ determined from separate experiments, as described elsewhere [16]. All gases were 5N5 quality acquired from Airgas.

\section{Results and discussion}

Cyclic voltammetry was used to show how the surface coverage by a "static" cyanide adlayer on $\mathrm{Pt}(111)$ affects the potential-dependent (“dynamic") adsorption of $\mathrm{H}_{\text {upd }}, \mathrm{OH}_{\mathrm{ad}}$ and $\mathrm{HSO}_{4 \mathrm{ad}}$ in sulfuric acid solutions (Figure 1). The voltammetric profile of $\mathrm{Pt}(111)$ in $0.05 \mathrm{M}$ $\mathrm{H}_{2} \mathrm{SO}_{4}$ (Fig. 1a) is divided in three potential regions: (i) the $\mathrm{H}_{\text {upd }}$ potential region between $0.05 \mathrm{~V}$ and $0.35 \mathrm{~V}$; (ii) adsorption of (bi)sulfate ions between $0.35 \mathrm{~V}$ and $0.6 \mathrm{~V}$, with a distinctive sharp adsorption peak (so-called butterfly peak) related to disorder-order transition of $\mathrm{HSO}_{4 \mathrm{ad}}[17,18]$; and (iii) 0.6 to $0.9 \mathrm{~V}$ where a small hump corresponds to $\mathrm{OH}_{\mathrm{ad}}$ adsorption. For comparison, the cyclic voltammetric (CV) profile of $\mathrm{Pt}(111)$ in $0.1 \mathrm{M} \mathrm{HClO}_{4}$ is displayed in Fig. 1a. Consistent with the previous literature [12], while there is no difference in the $\mathrm{H}_{\text {upd }}$ region between these two electrolytes, in $0.1 \mathrm{M} \mathrm{HClO}_{4}$ a characteristic reversible peak centered at $0.8 \mathrm{~V}$ (also called the butterfly feature) corresponds to adsorption of $\mathrm{OH}^{-}$. Nevertheless, Figures $1 \mathrm{~b}-\mathrm{f}$ show that in sulfuric acid solution the potential-dependent adsorption of spectator species is altered on the $\mathrm{Pt}(111)-\mathrm{CN}_{\mathrm{ad}}$ electrode. Three characteristic voltammetric features are noteworthy. First, the $\mathrm{H}_{\text {upd }}$ region is extended up to ca. $0.6 \mathrm{~V}$, suggesting the existence of electrostatic interactions (dipoledipole forces) between partially positively charged $\mathrm{H}_{\text {upd }}$ and a partially negatively charged $\mathrm{CN}_{\mathrm{ad}}$. Notice also that while between 0.05 and $0.4 \mathrm{~V}$ the adsorption profile (peak shape) on $\mathrm{Pt}-\mathrm{CN}-\mathrm{H}_{\text {upd }}$ is consistent with a Frumkin-like adsorption, at more positive potential the adsorption of $\mathrm{H}_{\text {upd }}$ is also controlled by some attractive forces between $\mathrm{CN}_{\mathrm{ad}}$ and $\mathrm{H}_{\text {upd }}$. Second, the formation of the butterfly feature in region (ii) is rapidly suppressed even at $\Theta_{\mathrm{CNad}}=0.04 \mathrm{ML}$, confirming 
previous observation that an ordered adsorption of bisulfate anions requires large ensemble of $\mathrm{Pt}$ surface sites. A close inspection of Fig. 1 reveals that increase by $\mathrm{CN}_{\mathrm{ad}}$ to $0.16 \mathrm{ML}$ leads to a further decrease in $\Theta_{\mathrm{HSO} 4 \mathrm{ad}}$ so that at ca. $\Theta_{\mathrm{CNad}}=0.31 \mathrm{ML}$ the adsorption of $\mathrm{HSO}_{4}$ is observed only above $0.6 \mathrm{~V}$ (a small increase in the "double layer" pseudocapacitive feature). Complete suppression of bisulfate anions appears to occur on the surface which is covered by $\Theta_{\mathrm{CNad}}=0.36$ ML. Third, the surface coverage and the potential window of adsorption of $\mathrm{OH}_{\mathrm{ad}}$ is also dependent on $\Theta_{\mathrm{CNad}}$. Due to decrease in the surface coverage by $\mathrm{HSO}_{4 \mathrm{ad}}$ an initial enhanced $\mathrm{OH}$ adsorption is observed already at $\Theta_{\mathrm{CNad}}=0.04 \mathrm{ML}$ (a peak at 0.9 V). Further increase in $\Theta_{\mathrm{CNad}}$, however, is first mirrored by the concomitant increase in $\Theta_{\mathrm{OHad}}$, that later becomes suppressed for $\Theta_{\mathrm{CNad}}>0.31 \mathrm{ML}$. It is reasonable to suggest that the observed relationship between $\Theta_{\mathrm{CNad}}$ and $\Theta_{\mathrm{OHad}}$ is controlled by a delicate balance between the surface coverage by $\mathrm{CN}_{\mathrm{ad}}$ and bisulfate anions and thus the availability of Pt sites for $\mathrm{OH}_{\mathrm{ad}}$ formation that requires a single Pt site. Unlike $\mathrm{H}_{\text {upd }}$, the peak potential for $\mathrm{OH}_{\mathrm{ad}}$ is shifted towards more positive potentials relative to one observed in perchloric acid solution because of the existence of lateral repulsion between partially negative charges of $\mathrm{CN}_{\mathrm{ad}}$ and $\mathrm{OH}_{\mathrm{ad}}$. All of these changes observed for the "dynamic" spectators can be related to the nature of the Pt-cyanide bonding and its surface structure, as they can interact through both electrostatic forces and site ensemble selectivity. Taken together, we conclude that $\mathrm{CN}_{\mathrm{ad}}$ "static" layer can affect adsorption of "dynamic" adsorbates by either modifying or eliminating surface site-ensembles and by electrostatic dipole-dipole forces.

In our previous work we used rotating disk electrode (RDE) method to study the ORR on $\operatorname{Pt}(111)$ modified by an optimal coverage of $\mathrm{CN}_{\mathrm{ad}}$ [12]. Of concern here is to monitor how the peroxide formation depends on various surface coverages of both the "static" and "dynamic" spectators. For monitoring simultaneously the ORR and concomitant peroxide formation we employed the RRDE method. Selected polarization curves for the ORR on $\mathrm{Pt}(111)-\mathrm{CN}_{\mathrm{ad}}$ disk electrode and corresponding peroxide oxidation currents on the ring electrode are summarized in Figures $2 \mathrm{a}$ and $2 \mathrm{~b}$, respectively, also including the results on $\mathrm{Pt}(111)$ in $0.1 \mathrm{M} \mathrm{HClO}_{4}$, for comparison. Qualitatively, peroxide formation occurs below $0.5 \mathrm{~V}$, e.g., in the "double layer" and $\mathrm{H}_{\text {upd }}$ potential regions. For our purposes here we will first focus on the role of $\mathrm{CN}_{\mathrm{ad}}$ on the reaction pathway and then we use the RRDE polarization curves recorded in Figures $2 \mathrm{a}$ and $2 \mathrm{~b}$ to explore the manner and extent of $\mathrm{Pt}-\mathrm{OH}_{\mathrm{ad}}$ and $\mathrm{Pt}-\mathrm{H}_{\text {upd }}$ interactions may affect the ORR on $\operatorname{Pt}(111)-\mathrm{CN}_{\mathrm{ad}}$. 
As expected, activity-selectivity relationships are strongly dependent on the $\Theta_{\mathrm{CNad}}$. A quantitative analysis of the results depicted in Figures 1a-f, 2a and 2b, summarized in the form of $\Theta_{\mathrm{CNad}}$ Vs. ORR activity at $0.85 \mathrm{~V}$ (Fig. 2c) and $\Theta_{\mathrm{CNad}}$ Vs. ring currents at $0.6 \mathrm{~V}$ (Fig. 2d) provides insight into the role of the surface coverage of adsorbed species $\left(\Theta_{\mathrm{s}}\right)$ on the rate of the ORR and peroxide production. While $0.85 \mathrm{~V}$ was chosen because in this region the ORR is under kinetic control, $0.6 \mathrm{~V}$ is an optimal potential where the role of $\mathrm{CN}_{\mathrm{ad}}$ can be studied without an interference with the $\mathrm{H}_{\text {upd }}$ potential region. Notice that by changing $\Theta_{\mathrm{CNad}}$ the surface coverage by bisulfate will affect the activity of ORR (blocking $\mathrm{O}_{2}$ adsorption) but not the peroxide production after the ORR starts. This is because desorption of large bi-sulfate anions leave behind an ensemble of at least four Pt sites that are required for further reduction of $\mathrm{H}_{2} \mathrm{O}_{2} *$ to water (see the result for the ORR on $\mathrm{Pt}(111)$ in $0.05 \mathrm{M} \mathrm{H}_{2} \mathrm{SO}_{4}$ ). Thus, one can anticipate that at $0.6 \mathrm{~V}$ it is indeed possible to explore the role of $\mathrm{CN}_{\mathrm{ad}}$ on the functional links between activity and selectivity. Figure $2 \mathrm{e}$ shows the fraction of $\mathrm{H}_{2} \mathrm{O}_{2} *\left(\mathrm{x}_{\mathrm{H} 2 \mathrm{O} 2}\right)$ produced at $0.6 \mathrm{~V}$ as well as the production of $\mathrm{H}_{2} \mathrm{O}$ (a $4 \mathrm{e}$ - process). The fraction of peroxide is calculated using the equation: $[16,19]:$

$$
H_{2} \mathrm{O}_{2}(\%)=\frac{2 I_{\text {ring }} / N}{I_{\text {disk }}+\left(I_{\text {ring }} / N\right)}
$$

where $I_{\text {ring }}$ and $I_{\text {disk }}$ are ring and disc currents at $0.6 \mathrm{~V}$ and $N$ is the collection efficiency (determined as 0.24). As expected, for high $\mathrm{CN}_{\mathrm{ad}}$ coverages $\left(\Theta_{\mathrm{CNad}}>0.36 \mathrm{ML}\right)$ very small currents for ORR are observed, signaling that the Pt sites for adsorption of $\mathrm{O}_{2}$ are highly blocked by $\mathrm{CN}_{\mathrm{ad}}$. This observation is in harmony with $\mathrm{CVs}$ depicted in Figures 1e to 1f, and with the fact that at high $\Theta_{\mathrm{CNad}}$ on $\mathrm{Pt}(111)$ adopts an ordered close packed structure [20-22]. Even more striking is the effect of $\mathrm{CN}_{\mathrm{ad}}$ on the selectivity, as for $\Theta_{\mathrm{CNad}}>0.31 \mathrm{ML}$ the ORR almost entirely goes through the $2 \mathrm{e}^{-}$pathway generating $\mathrm{H}_{2} \mathrm{O}_{2}$ (see Fig. 2e). As proposed above, under this experimental conditions the selectivity is predominantly governed by the lack of large Pt ensembles (at least $4 \mathrm{Pt}$ atoms) needed to further reduce $\mathrm{H}_{2} \mathrm{O}_{2} *$ to water. As expected, Figures $2 \mathrm{c}$ and $2 \mathrm{~d}$ show a $\Theta_{\mathrm{CNad}}$-controlled "volcano" like behavior; e.g., by decreasing the $\Theta_{\mathrm{CNad}}$ the ORR first increases, reaching its maximum for $\Theta_{\mathrm{CNad}}=0.29 \mathrm{ML}$, and then decreases so that for $\Theta_{\mathrm{CNad}}$ $<0.1$ ML the activity approaches same as on bare $\mathrm{Pt}(111)$ in sulfuric acid solution (Fig 2a). 
Also worth noting briefly is that in certain potential range the activity-selectivity relationships are controlled by the combined effects of $\Theta_{\mathrm{CNad}}$ and $\Theta_{\mathrm{s}}$ of dynamic spectators. Two potential regions are of particular interest; namely, the potential window where on $\operatorname{Pt}(111)-\mathrm{CN}_{\mathrm{ad}}$ surface either $\mathrm{OH}_{\mathrm{ad}}$ or $\mathrm{H}_{\text {upd }}$ are adsorbed on $\mathrm{CN}_{\mathrm{ad}}$ - free Pt sites (see Fig. 1, regions $i$ and iii). In contrast to adsorption of bisulfate ions, these two dynamic spectators need only one Pt site for adsorption. It is reasonable to anticipate that reactivity and selectivity will depend strongly on the intermolecular interactions between adsorbed species. For example, the onset potential for the ORR is strongly dependent on $\Theta_{\mathrm{OHad}}$, the effect arising from the need of removal (reduction) of $\mathrm{OH}_{\mathrm{ad}}$ that is controlling adsorption of $\mathrm{O}_{2}$. Interestingly, irrespectively of $\Theta_{\mathrm{CNad}}$ the ORR below $0.8 \mathrm{~V}$ (region iii, Fig. 1) proceeds without peroxide formation. In contrast, for the same $\mathrm{CN}_{\mathrm{ad}}$ coverages in the $\mathrm{H}_{\text {upd }}$ potential region the ORR is always accompanied by peroxide production. A possible origin for this difference could be due both distinct nature of $\mathrm{H}_{\mathrm{upd}}-\mathrm{H}_{\text {upd }} \mathrm{vs} \mathrm{OH}_{\mathrm{ad}}-\mathrm{OH}_{\mathrm{ad}}$ interactions and/or the role $\mathrm{H}_{\text {upd }}$ and $\mathrm{OH}_{\mathrm{ad}}$ may have in the overall reaction pathway. For instance, while $\mathrm{H}_{\mathrm{upd}}$ tends to form a randomly distributed disordered structure (the Frumkin-type isotherm with repulsive lateral interactions), it appears that $\mathrm{OH}_{\mathrm{ad}}$ adlayer has a tendency to cluster on the $\mathrm{Pt}(111)$ surface, at least at lower $\mathrm{OH}_{\mathrm{ad}}$ coverages. As a consequence, a small $\Theta_{\mathrm{Hupd}}$ can alter significantly the availability of $\mathrm{Pt}$ ensembles required for breaking the $\mathrm{O}-\mathrm{O}$ bond in $\mathrm{H}_{2} \mathrm{O}_{2}$; thus acting as a third-body effect. On the other hand, if $\mathrm{OH}_{\mathrm{ad}}$ has a tendency to cluster on the $\mathrm{Pt}(111)$ surface then there are always free sites (ensemble of four atoms) for further reduction of the peroxide intermediates. Clearly, the interactions observed between static and dynamic spectators can help us to infer not only that certain ensemble of Pt sites is required for the $4 \mathrm{e}-$ reduction but, in addition, provide more substantial evidence on how the switching between the "peroxide pathway" and the "water pathway" might take place.

\section{Conclusion}

By combining the use of a "static" spectator, $\left(\mathrm{CN}_{\mathrm{ad}}\right.$, with a known surface coverage $)$ with the common "dynamic" spectators observed in sulfuric acid solutions ( $\mathrm{H}_{\text {upd }}, \mathrm{HSO}_{4 \mathrm{ad}}$ and $\left.\mathrm{OH}_{\mathrm{ad}}\right)$ we were able to propose the functional links between activity and selectivity for the ORR. These relationships can be simply explained by balancing electronic and ensemble effects of adsorbed spectators without invoking intermediate adsorption energy arguments. Although this study has 
focused on the $\mathrm{Pt}(111)-\mathrm{CN}_{\mathrm{ad}} / \mathrm{H}_{2} \mathrm{SO}_{4}$ interface, the results and insight gained here are valuable for controlling another dimension in the properties of electrochemical interfaces.

\section{Acknowledgments}

This work was supported by the Office of Science, Office of Basic Energy Sciences, Division of Materials Sciences, U.S. Department of Energy, under contract DE-AC02-06CH11357 (BESDMSE). E. G. Ciapina acknowledges support from FAPESP (grant numbers 2010/02905-2 and 2013/16930-7).

\section{Figure Captions}

Figure 1 - Cyclic voltammograms of $\mathrm{Pt}(111)-\mathrm{CN}_{\mathrm{ad}}$ electrode in several distinct $\mathrm{CN}_{\mathrm{ad}}$ coverages in $0.05 \mathrm{~mol} \mathrm{~L}^{-1} \mathrm{H}_{2} \mathrm{SO}_{4}$ electrolytes. a) bare $\mathrm{Pt}(111)$ in both $\mathrm{H}_{2} \mathrm{SO}_{4}$ and $\mathrm{HClO}_{4}$. (b) $\mathrm{Pt}(111)$ covered with $\theta_{\mathrm{CNad}}=0.04 \mathrm{ML}$, (c) $0.16 \mathrm{ML}$, (d) $0.31 \mathrm{ML}$, (e) $0.36 \mathrm{ML}$ and (f) $0.45 \mathrm{ML}$. Potential region $i$ (dashed), $i i$ (solid) and $i i i\left(\right.$ dotted) highlights the presence of $H_{\mathrm{UPD}}$, adsorbed (bi)sulfate and $\mathrm{OH}_{\mathrm{ad}}$, respectively. All experiments were conducted at $25^{\circ} \mathrm{C}$ with $50 \mathrm{mVs}^{-1}$ sweep rates.

Figure 2 - RRDE results for ORR in $\mathrm{Pt}(111)-\mathrm{CN}_{\mathrm{ad}}$ electrode in several distinct $\mathrm{CN}_{\mathrm{ad}}$ coverages in $0.05 \mathrm{~mol} \mathrm{~L}^{-1} \mathrm{H}_{2} \mathrm{SO}_{4}$. The disk and ring currents are shown in a) and b), respectively. Polarization curves for $\mathrm{Pt}(111)$ in pure $\mathrm{HClO}_{4}$ are included for comparison. "Volcano"-like trend with varying $\Theta_{\mathrm{CNad}}$ was measured at $0.85 \mathrm{~V}$ for activity (c) and peroxide production at $0.60 \mathrm{~V}$ (d). ORR selectivity determined at $0.60 \mathrm{~V}$ is shown in (e), using Eq. 1. 


\section{References}

[1] H.A. Gasteiger, N.M. Markovic, Chemistry. Just a dream--or future reality?, Science. 324 (2009) 48-9.

[2] M.K. Debe, Electrocatalyst approaches and challenges for automotive fuel cells, Nature. 486 (2012) 43-51.

[3] M.H. Shao, R.R. Adzic, Spectroscopic identification of the reaction intermediates in oxygen reduction on gold in alkaline solutions, J. Phys. Chem. B. 109 (2005) 1656316566.

[4] N. Ohta, K. Nomura, I. Yagi, Adsorption and electroreduction of oxygen on gold in acidic media: In situ spectroscopic identification of adsorbed molecular oxygen and hydrogen superoxide, J. Phys. Chem. C. 116 (2012) 14390-14400.

[5] J.K. Nørskov, J. Rossmeisl, A. Logadottir, L. Lindqvist, J.R. Kitchin, T. Bligaard, et al., Origin of the Overpotential for Oxygen Reduction at a Fuel-Cell Cathode, J. Phys. Chem. B. 108 (2004) 17886-17892.

[6] N.M. Markovic, P.R. Jr, Surface science studies of model fuel cell electrocatalysts, Surf. Sci. Rep. 45 (2002) 117-229.

[7] F.C. Nart, T. Iwasita, M. Weber, Vibrational spectroscopy of adsorbed sulfate on Pt(111), Electrochim. Acta. 39 (1994) 961-968.

[8] F.C. Nart, T. Iwasita, An FTIR study of adsorbed sulfate species on polycrystalline platinum with application of group theory to the problem of band assignment for adsorbed species, J. Electroanal. Chem. 322 (1992) 289-300.

[9] V.R. Stamenkovic, N.M. Markovic, P.N. Ross, Structure-relationships in electrocatalysis: oxygen reduction and hydrogen oxidation reactions on $\mathrm{Pt}(111)$ and $\mathrm{Pt}(100)$ in solutions containing chloride ions, J. Electroanal. Chem. 500 (2001) 44-51.

[10] N.M. Markovic, H.A. Gasteiger, B.N. Grgur, P.N. Ross, Oxygen reduction reaction on Pt(111): effects of bromide, J. Electroanal. Chem. 467 (1999) 157-163.

[11] H.A. Gasteiger, N.M. Markovic, P.N. Ross, Bromide Adsorption on Pt ( 111 ): Adsorption Isotherm and Electrosorption Valency Deduced from RRD Pt ( 111 ) E Measurements, Langmuir 12 (1996) 1414-1418.

[12] D. Strmcnik, M. Escudero-Escribano, K. Kodama, V.R. Stamenkovic, A. Cuesta, N.M. Marković, Enhanced electrocatalysis of the oxygen reduction reaction based on patterning of platinum surfaces with cyanide, Nat. Chem. 2 (2010) 880-5. 
[13] M. Escudero-Escribano, G.J. Soldano, P. Quaino, M.E. Zoloff Michoff, E.P.M.M. Leiva, W. Schmickler, et al., Cyanide-modified Pt(111): Structure, stability and hydrogen adsorption, Electrochim. Acta. 82 (2012) 524-533.

[14] D.S. Strmcnik, P. Rebec, M. Gaberscek, D. Tripkovic, V. Stamenkovic, C. Lucas, et al., Relationship between the Surface Coverage of Spectator Species and the Rate of Electrocatalytic Reactions, J. Phys. Chem. C. 111 (2007) 18672-18678.

[15] B. Genorio, D. Strmcnik, R. Subbaraman, D. Tripkovic, G. Karapetrov, V.R. Stamenkovic, et al., Selective catalysts for the hydrogen oxidation and oxygen reduction reactions by patterning of platinum with calix[4]arene molecules, Nat Mater. 9 (2010) 998-1003.

[16] U.A. Paulus, T.J. Schmidt, Oxygen reduction on a high-surface area Pt/Vulcan carbon catalyst: a thin-film rotating ring-disk electrode study, J. Electroanal. Chem. 495 (2001) 134-145.

[17] A.M. Funtikov, U. Stimming, R. Vogel, Anion adsorption from sulfuric acid solutions on Pt(111) single crystal electrodes, J. Electroanal. Chem. 428 (1997) 147-153.

[18] N. García, V. Climent, J.M. Orts, J.M. Feliu, A. Aldaz, Effect of pH and Alkaline Metal Cations on the Voltammetry of Pt(111) Single Crystal Electrodes in Sulfuric Acid Solution, ChemPhysChem. 5 (2004) 1221-1227.

[19] J.S. Jirkovský, M. Halasa, D.J. Schiffrin, Kinetics of electrocatalytic reduction of oxygen and hydrogen peroxide on dispersed gold nanoparticles, Phys. Chem. Chem. Phys. 12 (2010) 8042-52.

[20] A. Cuesta, At Least Three Contiguous Atoms Are Necessary for CO Formation during Methanol Electrooxidation on Platinum, J. Am. Chem. Soc. 128 (2006) 13332-13333.

[21] C. Stuhlmann, I. Villegas, M.J. Weaver, Scanning tunneling microscopy and infrared spectroscopy as combined in situ probes of electrochemical adlayer structure. Cyanide on Pt(111), Chem. Phys. Lett. 219 (1994) 319-324.

[22] C. Stuhlmann, Characterization of an electrode adlayer by in-situ infrared spectroscopy: cyanide on Pt(111), Surf. Sci. 335 (1995) 221-226. 

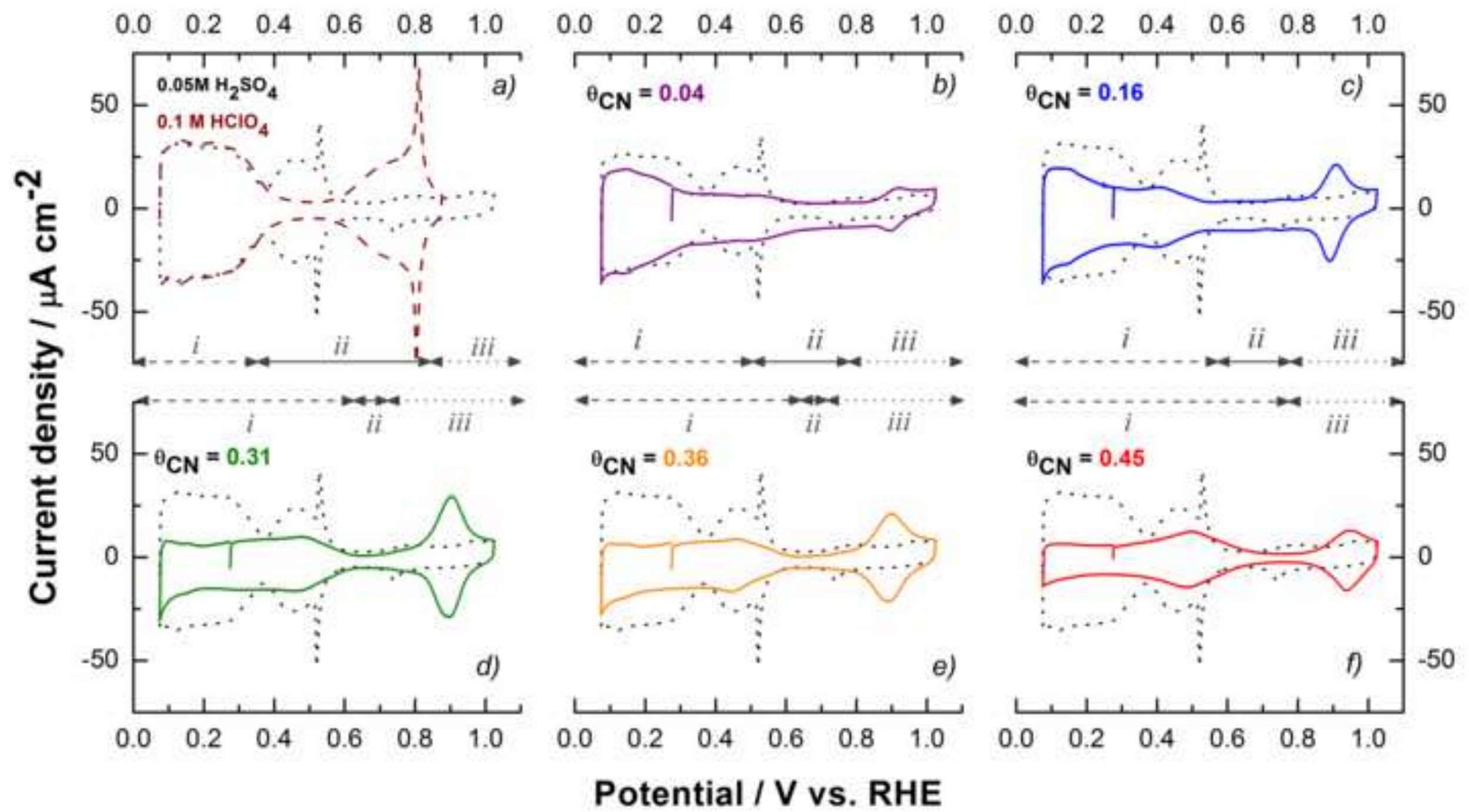

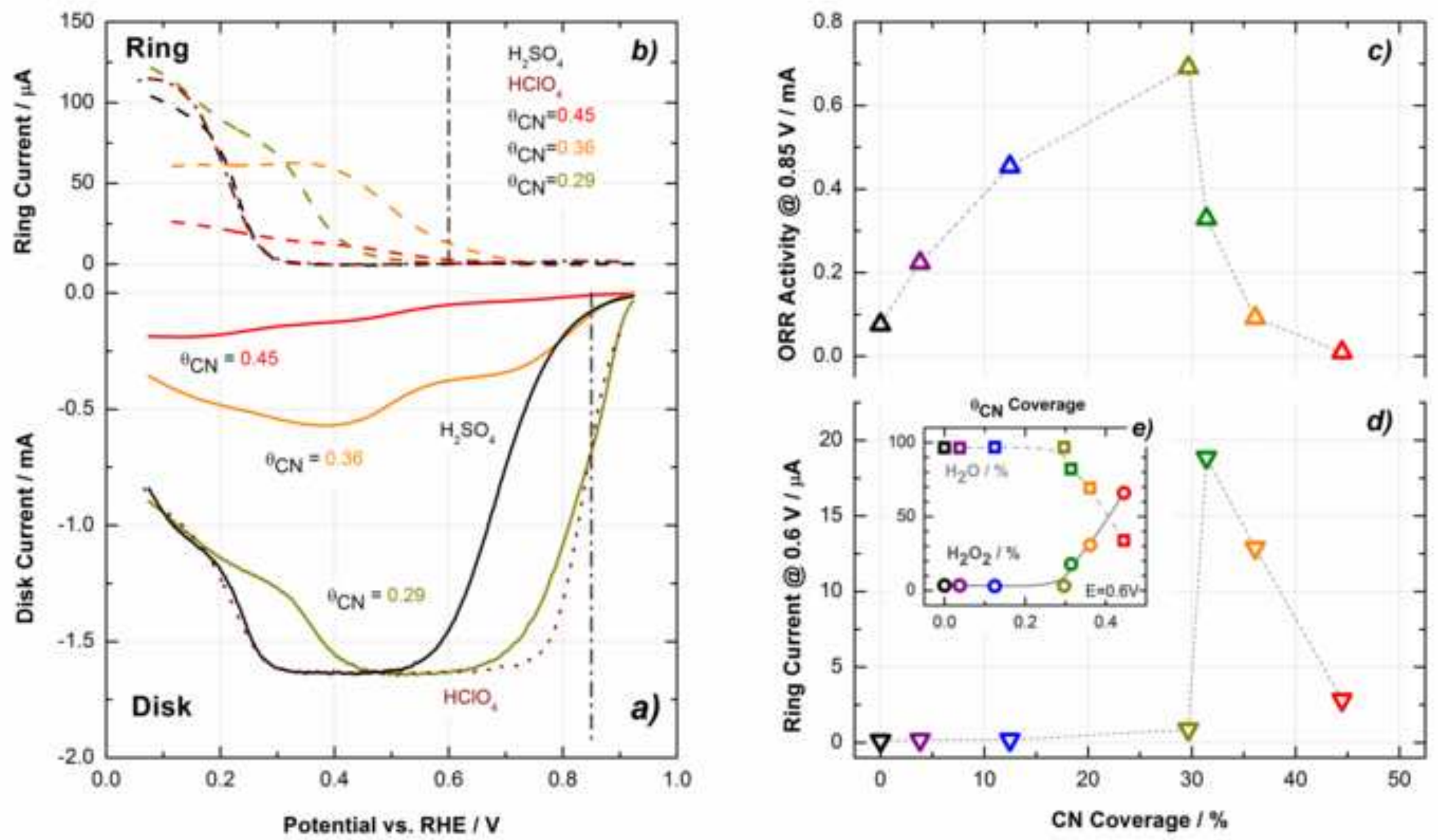